Калоева С.К., Слепушкин В.Д.

Северо-Осетинская государственная медицинская академия

Республиканский клинический центр фтизиопульмонологии» МЗ РСО-Алания

Кафедра анестезиологии, реаниматологии и интенсивной терапии СОГМА

\title{
ОПИОИДСБЕРЕГАЮЩИЕ ТЕХНОЛОГИИ У НАРКОЗАВИСИМЫХ ПАЦИЕНТОВ
}

\section{ЦЕЛЬ ИССЛЕДОВАНИЯ}

Повысить качество проведения анестезиологического пособия у наркозависимых пациентов, путем разработки и внедрения опиоидсберегающих методик в торакальной хирургии.

МАТЕРИАЛ И МЕТОДЫ ИССЛЕДОВАНИЯ

Всего включено в анализ 409 пациентов, у которых диагностировалась неактивная фаза туберкулезного процесса легочной этиологии и которым по показаниям выполнялась видеоассистированная торакоскопия, из них 193 человек опиоиднезависимые (контрольная группа) и 216 человека Опиоидзависимые (основная группа). Возраст пациентов составлял от 20 до 60 лет (в среднем 38,6+6,2 года).

Критерии включения пациента в исследование:

- информированное согласие пациента на участие в исследовании;

- мужской пол;

- физический статус класса ASAIIA и ASAIIB;

- добровольное информирование о наличии вредных привычек;

- показания к видеоассистированная торакоскопия;

- показания к тому или иному виду анестезиологического пособия (тотальная внутривенная анестезия или низкопоточная ингаляционная анестезия 1 л/мин $-1$

л/мин Воздух+02).

Критерии исключения из исследования:

- отказ пациента от участия в исследовании (отсутствие информированного согласия);

- физический статус класса ASAIII;

- переход на открытую операцию;

- противопоказания к проведению анестезиологического пособия по типу ТВА или низкопоточной ингаляционной анестезии;

- наличие в анамнезе поливалентной аллергии, сахарного диабета, острого нарушения мозгового кровообращения, эпилепсии, декомпенсированных нарушений сердечно-сосудистой системы, органического поражения центральной нервной системы;

- интраоперационная кровопотеря свыше 500 мл.

Из сопутствующих вредных привычек все пациенты указывали на употребление табачных изделий со стажем от 6 до 36 лет. 67\% пациентов признали хроническое употребление алкоголя в течение от 3 до 20 лет.

Диагноз - хроническая наркозависимость устанавливалась на основании обязательной консультации нарколога.

Показания к оперативному вмешательству всем исследуемым больным было поражение легких вследствие заболевания туберкулеза легких

Оперативное вмешательство, проведённые исследуемым пациентам, в основном заключались в ВАТС, лобэктомия или резекции (правого или левого легкого)

Все пациенты в течение от 2 до 6 лет получали комплекс препаратов, необходимых для лечения туберкулеза.

У всех пациентов выявлен антитела или антигены вируса A, В или C, или их сочетание.

За 6 суток до проведения анестезиологического пособия для проведения гепатопротекции использовали метаболотропный препарат ремаксол (янтарная кислота+инозин+никотинамид+мелгамин+метионин).

Группы пациентов, их количество, виды анестезиологического пособия и предоперационная подготовка приведены в таблице 1.

РЕЗУЛЬТАТЫ И ИХ ОБСУЖДЕНИЕ Таким образом, удалось, в порядке убывания, выстроить значимость того или иного биохимического показателя, 
Количество пациентов в группах

\begin{tabular}{|c|c|}
\hline $\begin{array}{c}\text { Группы пациентов в зависимости от вида анестезиологического } \\
\text { пособия и предоперационной метаболотропной терапии }\end{array}$ & $\begin{array}{c}\text { Количество } \\
\text { пациентов }\end{array}$ \\
\hline 1А опиоиднезависимый пациент + ТВА & 31 \\
\hline 1Б - опиоиднезависимый пациент + ремаксол + ТВА & 32 \\
\hline 1B - опиоидзависимый пациент + ТВА & 31 \\
\hline $1 \Gamma$ - опиоидзависимый пациент + ремаксол + ТВА & 32 \\
\hline $\begin{array}{l}2 \mathrm{~A}-\text { опиоднезависимый пациент }+ \text { ингаляционная анестезия } \\
\text { севораном }\end{array}$ & 32 \\
\hline $\begin{array}{l}\text { 2Б- опиоиднезависимый пациент }+ \text { ремаксол }+ \text { ингаляционная } \\
\text { анестезия севораном }\end{array}$ & 34 \\
\hline $\begin{array}{l}\text { 2B - опиоидзависимый пациент }+ \text { ингаляционная анестезия } \\
\text { севораном }\end{array}$ & 33 \\
\hline $\begin{array}{l}\text { 2Г-опиоидзависимый пациент }+ \text { ремаксол }+ \text { ингаляционная } \\
\text { анестезия севораном }\end{array}$ & 32 \\
\hline $\begin{array}{l}3 \mathrm{~A}-\text { опиоиднезависимый пациент }+ \text { ингаляционная анестезия } \\
\text { десфлураном }\end{array}$ & 32 \\
\hline $\begin{array}{l}\text { ЗБ - опиоиднезависимый пациент }+ \text { ремаксол }+ \text { ингаляционная } \\
\text { анестезия десфлураном }\end{array}$ & 32 \\
\hline $\begin{array}{l}\text { 3В - опиоидзависимый пациент }+ \text { ингаляционная анестезия } \\
\text { десфлураном }\end{array}$ & 33 \\
\hline $\begin{array}{l}\text { 3Г - опиоидзависимый пациент }+ \text { ремаксол }+ \text { ингаляционная } \\
\text { анестезия десфлураном }\end{array}$ & 32 \\
\hline $\begin{array}{l}3 \text { Д - опиоидзависимый пациент + тиатриазолин + ингаляционная } \\
\text { анестезия десфлураном }\end{array}$ & 23 \\
\hline ИТОГО & 409 \\
\hline
\end{tabular}

Табл. 2

Сравнительная оценка времени назначения первой инъекции морфина гидрохлорида время после операции ( $\geq 6$ баллов по шкале ВАШ)

\begin{tabular}{|c|c|}
\hline Группы & $\begin{array}{c}\text { Время первой инъекции морфина гидрохлорида в } \\
\text { послеоперационном периоде }\end{array}$ \\
\hline $1 \mathrm{~A}$ & $8,1 \pm 1,1$ часа \\
\hline 1Б & $8,4 \pm 1,3$ часа \\
\hline 1В & $8,4 \pm 1,3$ часа \\
\hline $1 \Gamma$ & $4,4 \pm 0,5$ часа \\
\hline $2 \mathrm{~A}$ & $8,3 \pm 1,3$ часа \\
\hline 2 Б & $8,5 \pm 1,3$ часа \\
\hline $2 \mathrm{~B}$ & $3,1+0,1$ часа \\
\hline $2 \Gamma$ & $3,2 \pm 0,2$ часа \\
\hline $3 \mathrm{~A}$ & $7,6+0,4$ часа \\
\hline 3 Б & $7,9 \pm 0,4$ часа \\
\hline $3 \mathrm{~B}$ & $4,6 \pm 0,4$ часа \\
\hline $3 \Gamma$ & $5,8 \pm 0,4$ часа \\
\hline 3 (Д & $5,3 \pm 0,3$ часа \\
\hline
\end{tabular}


характеризующего функциональную активность печени, в отношении снижения потребности в наркотических препаратах у опиоидзависимых пациентов.

Исходя из приведенных данных, мы смогли ответить на стратегический вопрос: какой вид анестезиологического пособия наиболее приемлем у опиоидзависимых пациентов. печень и восстанавливает чувствительность рецепторного аппарата (холинергическиъх, опиатных, ГАМК-ергических рецепторов). Последнее наиболее важно в отношении восстановления чувствительности мю-опиатных рецепторов, что, с практической точки зрения, позволяет уменьшить использование опиоидов без ухудшения качества анестезии как во

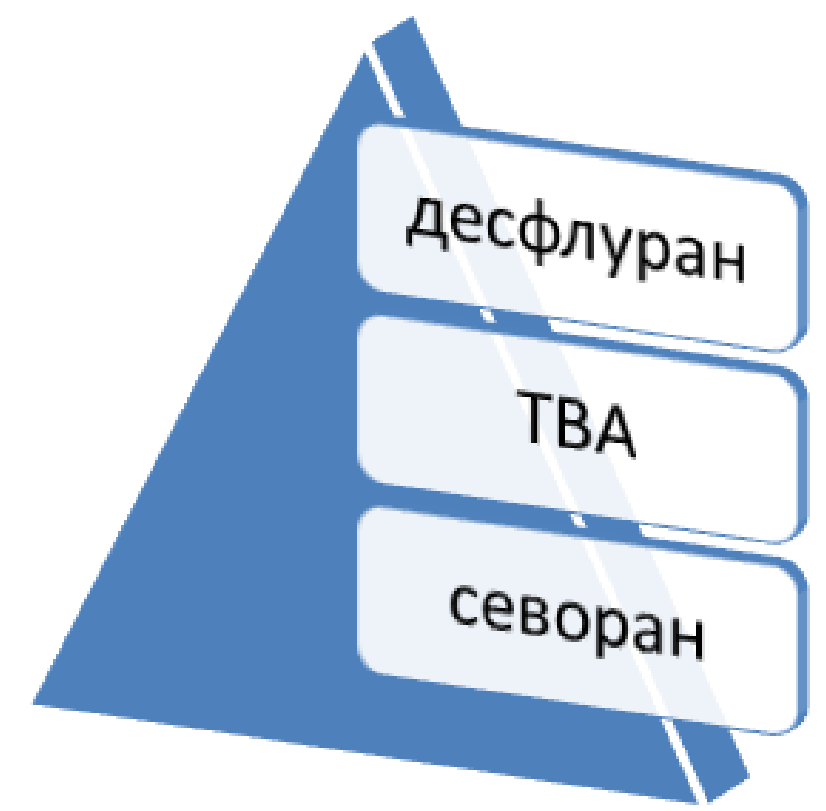

Рис. 1

Расположение основных видов анестетиков для анестезиологического пособия по эффективности относительно повреждения функции печени и рецепторного аппарата

На первом месте стоит анестезиологическое пособие по схеме низкопоточной ингаляционной анестезии с использованием десфлурана. Но втором месте - тотальная внутривенная анестезия с использованием в качестве гипнотика пропофола. Наименее желательна у опиоидзависимых пациентов низкопоточная ингаляционная анестезия с использованием севорана.

Мы получили следующие эффекты при использовании препарата ремаксола (рис. 4).

В результате проведенного исследования можно констатировать, что рассмотрены оба анонсированных стратегических направления, а именно: выбран наиболее щадящий метод анестезиологического обеспечения при проведении оперативных вмешательств на бронхолегочной системе у опиоидзависимых пациентов и разработана методология, которая в наибольшей степени защищает время проведения оперативного вмешательства, так и в ближайшем послеоперационном периоде.

\section{ЗАКЛЮЧЕНИЕ}

Проведенное исследование позволило повысить качество анестезии у опиоидзависимых пациентов путем разработки опиоидсберегающих технологий, основанных на гепатопротективной предоперационной подготовке, выявления основных видов анестетиков для анестезиологического пособия по эффективности относительно повреждения функции печени и рецепторного аппарата, и снижения интраоперационного расхода как наркотических, так и седативных препаратов.

1. Различные способы проведения анестезиологического пособия у опиоидзависимых пациентов с туберкулезом легких оказывают неоднозначное дополнительное токсическое влияние на функцию печени. Путем использования гепа- 


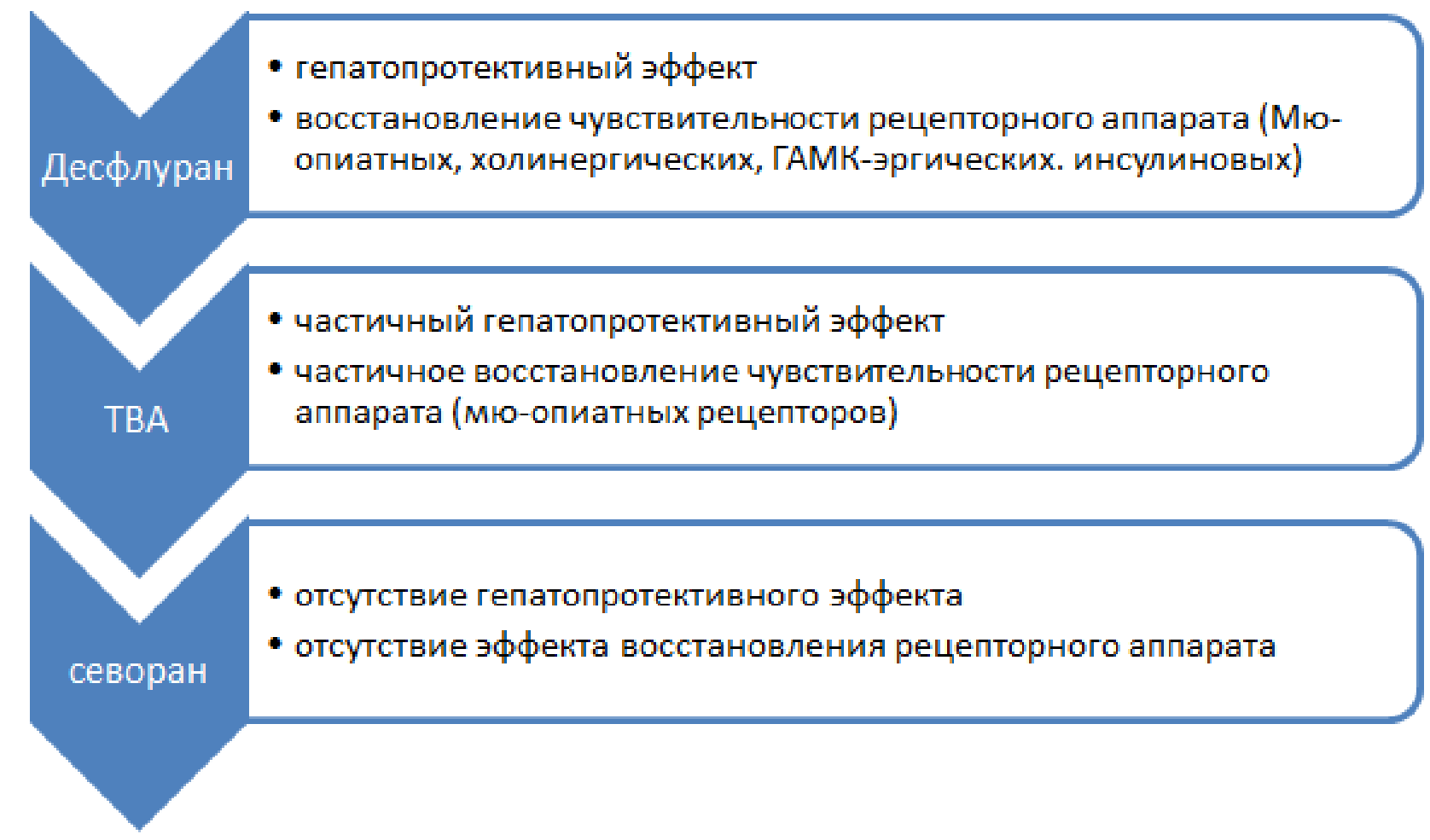

Рис. 2

Степень эффективности сочетания препаратов анестезиологического пособия с препаратом ремаксолом

топротективных препаратов возможно предотвратить повреждающее влияние препаратов для наркоза и тем самым уменьшить потребление опиоидов.

2. Как у опиоиднезависимых, так и опиоидзависимых пациентов с туберкулезом легких после проведения анестезиологического пособия по методу низкопоточной ингаляционной анестезии с использованием десфлурана не нарушает функциональное состояние печени. Проведение тотальной внутривенной анестезии с использованием гипнотика пропофола оказывает гепатотоксическое действие. Выраженное гепатотоксическое действие оказывает проведение низкопоточной анестезии с использованием севорана.

3. Трансформация опиоидных аналгетиков происходит в печени и напрямую зависит от ее состояния (уровня цитохрома P450), этим обуславливается выраженность токсического действие анестезиологического пособия на функциональное состояние печени, тем больше необходимо опиоидов как во время проведения анестезиологического пособия, так и в ближайшем послеоперационном периоде для адекватного обезболивания, 21

Калоева С.К. и соавт. разработанная стратегия позволяет достоверно уменьшить использование опиоидов без ухудшения качества анестезии как во время проведения оперативного вмешательства, так и в ближайшем послеоперационном периоде.

4. Увеличение токсического влияния анестезиологического пособия приводит к повышению использования агонистов ГАМК-ергических рецепторов, что связано с недостаточным воздействием наркотических аналгетиков на опиатные рецепторы и требуется дополнительная стимуляция обезболивающего эффекта через ГАМК а и ГАМК в рецепторы.

6. Активность фермента, характеризующего степень токсического повреждения печени гамма-глутамилтранспептидазы может быть критерием прогнозирования потребности в опиоидных препаратах, необходимых для адекватного обезболивания опиоидзависимых пациентов во время проведения анестезиологического пособия и в ближайшем послеоперационном периоде.

7. Гепатопротекторный препарат тиотриазолин улучшает функциональную активность печени у опиоидзависимых пациентов в предоперационном периоде, но 
не восстанавливает чувствительность опиатных рецепторов.

Литература

1. А. В. Ткачёв, А. С. Макаренко, Т. А. Девликамова, 3. Х. Яндиева / Применение новых методов лечения у больных с алкогольным гепатитом // Медицинский вестник Северного Кавказа, № 1, 2012 стр. 85-86

2. А.В. Смирнов, О.Б. Нестерова, Р.В. Голубев / Янтарная кислота и ее применение в медицине часть 1. Янтарная кислота: метаболит и регулятор метаболизм организма человека // Нефрология. 2014. Том 18. №2. стр. 33-41

3. А.В. Смирнов, О.Б. Нестерова, Р.В. Голубев / Янтарная кислота и ее применение в медицине часть 2. Применение янтарной кислоты в медицине // Нефрология. 2014. Том 18. №4. стр. 12-24

4. Алиев В.А. Сравнение уровня белка C100 при операциях на сонных артериях в условиях анестезии пропофолом и десфлураном. Тезисы Федерации анестезиологов и реаниматологов России. М. 2019. 5-6

5. Арбух Д.М., Абузарова Г.Р., Алексеева Г.С. / Опиоидные анальгетики в терапии болевых синдромов // Вестник анестезиологии и реаниматологии, Том 14, № 3, 2017 стр. 58-67

6. Bimbach D.J., Browne I.M., Kim A. et al. Identification of polysubstance abuse in the parturient// Br.J. Anesth.2001.87/ P/488-490

7. Brownlow H.A., Pappachan J. Pathophysiology of cocain abuse// EJA. 2002.19(6). P.395-411

8. Bryson E/O/? Frost E.A.M. Herioperative addiction/ Springer, 2012. 290 p.

9. BuvanerndranA., Kroin J.S. Multimodal analgesia for controlling acute postoperative pain// CurrOpin Anaesthesiol.2009. 22(5). P.212-227

10. Charlton J.E. / ed. Core curriculum for professional education in pain. 3rd ed. // Seattle: IASP Press; 2005.
Работа получила Премию Главы

РСО-Алания за 2020 год

\section{Сведения об авторах}

Калоева С.К.

К мед.н., Врач анестезиолог РКБ

г. Владикавказ.

Тел.l: + 7962 744-92-52

e-mail: svkaloeva@mail.ru,

Слепушкин В.Д.

Заведующий кафедрой анестезиологии и реаниматологии

ФГБОУ Во «Северо-Осетинская государственная медицинская

академия» Минздрава России,

г. Владикавказ;

Доктор медицинских наук;

Заслуженный деятель науки РФ, профессор;

Адрес: 362019

Республика Северная Осетия-Алания, г.Владикавказ, ул.Пушкинская, 40

e-mail:

sogma@minzdrav.alania.gov.ru 